\title{
Article \\ Gender Differences in Clinical Characteristics of Korean Temporomandibular Disorder Patients
}

\author{
Jung-Hwan Jo ${ }^{1,2} \mathbb{D}$ and Jin-Woo Chung ${ }^{1,2,3, *}$ \\ 1 Department of Oral Medicine, Seoul National University Dental Hospital, 101 Daehak-ro, Jongno-gu, \\ Seoul 03080, Korea; junghwanjo@snu.ac.kr \\ 2 Department of Oral Medicine and Oral Diagnosis, School of Dentistry, Seoul National University, \\ 101 Daehak-ro, Jongno-gu, Seoul 03080, Korea \\ 3 Dental Research Institute, Seoul National University, 101 Daehak-ro, Jongno-gu, Seoul 03080, Korea \\ * Correspondence: jwchung@snu.ac.kr; Tel.: +82-2-2072-3021; Fax: +82-2-744-9135
}

check for updates

Citation: Jo, J.-H.; Chung, J.-W Gender Differences in Clinical

Characteristics of Korean

Temporomandibular Disorder

Patients. Appl. Sci. 2021, 11, 3583.

https://doi.org/10.3390/app11083583

Received: 5 March 2021

Accepted: 13 April 2021

Published: 16 April 2021

Publisher's Note: MDPI stays neutral with regard to jurisdictional claims in published maps and institutional affiliations.

Copyright: (c) 2021 by the authors. Licensee MDPI, Basel, Switzerland. This article is an open access article distributed under the terms and conditions of the Creative Commons Attribution (CC BY) license (https:// creativecommons.org/licenses/by/ $4.0 /)$

\begin{abstract}
The aims of this study were to investigate the gender differences in signs and symptoms of Korean Temporomandibular Disorder (TMD) patients based on Research Diagnostic Criteria for Temporomandibular Disorders (RDC/TMD) and psychosocial characteristics. A total of 1052 patients with TMD were evaluated with a questionnaire for medical history, clinical symptoms, and contributing factors, clinical examination based on RDC/TMD, and radiographic examination. RDC/TMD axis II and Symptom Checklist-90-Revision (SCL-90-R) were administered to evaluate pain-related disability level and psychological status of patients. The prevalence of TMD was higher in women than men, and the women were older than the men. The women showed higher prevalence of myogenous pain, mixed pain, disc displacement without reduction, osteoarthritis, headache, subjective insomnia, pain intensity, number of positive muscle palpation, and the high disability group in the grade chronic pain scale. Gender was associated with the number of positive muscle palpation and maximum mouth opening. Pain intensity was not associated with gender, but with number of systemic comorbidities. Subjective symptoms, and clinical and psychological characteristics of patients with TMD showed gender differences. To achieve understanding of patient and increase of success rate of treatment of TMD, gender should be considered in patient evaluations and treatment approaches.
\end{abstract}

Keywords: temporomandibular disorders; gender; RDC/TMD; SCL-90-R; graded chronic pain scale

\section{Introduction}

Temporomandibular disorders (TMDs) are the most common musculoskeletal conditions in the oral and facial areas accompanied by pain and dysfunction in temporomandibular joint (TMJ) or masticatory muscles. Common signs and symptoms of TMD are jaw pain, joint sounds, limited mouth opening, chewing difficulty, and mandibular deviation. These symptoms may exist alone or in combination with persistent, repetitive, or chronic characteristics, and are often associated with psychological variables [1]. TMD are common problems, affecting about $7-15 \%$ of the adult population [2-5] and 1.5-2 times as many occurrences in women as in men [6].

Many clinical studies have reported a strong female predominance of clinical signs and symptoms of TMD. In a Swedish population study, TMD-related pain, joint sounds, and bruxism were significantly higher in women than men [7]. Other studies also found that women reported the TMD symptoms more frequently than men, such as joint sounds, pain on TMJ and masticatory muscles, and limitation of mouth opening [8-13]. In the other hand, earlier epidemiologic studies reported that there was no significant gender difference in the prevalence of clinical signs and symptoms of TMD in the general population $[14,15]$. However, research on the general population should be analyzed carefully, since it could be possible to underestimate gender differences [16]. 
Analyzing a patient's psychological profile is helpful to increase the success rate of management of TMD, since psychological factors have important roles in progression of TMD. However, studies about the psychosocial factors in TMD between genders have not shown a coincidence. Some studies suggested that women with TMD exhibited much higher stress, anxiety scores, and muscle tension than men $[17,18]$. Women also have shown more sensitive responses to stress than men [19]. However, other studies reported that there were no significant gender differences in depression, somatization, and graded chronic pain scale [20].

In addition to the female predominance of TMD, we expect that the clinical signs and symptoms can appear differently in both genders, and these differences may have different characteristics in the patients who are seeking for treatment from the general population.

The aim of this study was to investigate the gender differences in signs and symptoms of TMD patients who visited the dental clinic in Korea based on RDC/TMD and psychosocial characteristics.

\section{Materials and Methods}

\subsection{Subjects}

A total of 1052 consecutive patients with TMD who visited the TMJ and Orofacial Pain Clinic of Seoul National University Dental Hospital from September 2013 to March 2015 were studied. Patients with any major musculoskeletal defects, TMJ fracture, and neurological diseases known to affect the TMJ were excluded from the study. The research protocol was approved by the Institutional Review Board of the Seoul National University Dental Hospital (CRI 15006).

\subsection{Clinical Assessment}

All patients filled out the questionnaire about demographic and past medical and dental history: gender, age, comorbidities (cardiovascular, neurological, psychological, endocrine, respiratory, and urinary diseases), trauma history, and orthodontic treatment history. The clinical parameters were also included with pain duration, pain intensity, and TMD related symptoms, such as headache, insomnia, tinnitus, and sleep bruxism. Pain intensity was scored by the patient on a visual analog scale (VAS) and calculated according to the graded chronic pain scale [21].

Clinical evaluations were performed on all the patients based on the RDC/TMD [22]. According to the RDC/TMD axis I guidelines, the TMD patients were examined and divided into three pain subgroups; myogenous, arthrogenous, and mixed (both myogenous and arthrogenous) pain groups.

Other TMJ related assessments consisted with disc displacement (normal, disc displacement with reduction, and disc displacement without reduction), number of positive muscle palpation, maximum mouth opening, and asymmetry of occlusal contacts. Palpation was done on 20 masticatory muscle areas (right and left side); temporalis (anterior, middle, and posterior), masseter (origin, body, and insertion), posterior mandibular region, submandibular region, lateral pterygoid area, and tendon of the temporalis. Maximum mouth opening was measured the shortest distance between the upper and lower incisors at the midline in millimeters on opening the mouth as wide as possible regardless of pain. Asymmetry of occlusal contacts was defined by clinical examination using and articulating film, Accufilm II (Parkell, Inc., Edgewood, NY, USA) when differences in the number of occlusal contacts of premolar and molar between both sides are more than two [23].

\subsection{Radiological Evaluation}

Osteoarthritis was defined when condylar erosion or osteophyte were observed on radiographs routinely taken in the diagnostic procedure of TMD including orthopantomogram, TMJ tomogram, and transcranial radiograph. The radiographs were digitally generated by Orthopantomograph ${ }^{\circledR}$ OP 100 (Instrumentariu Dental, Tuusula, Finland). 


\subsection{Psychological Profiles}

The Korean version of the RDC/TMD axis II history questionnaire and the Symptom Checklist-90-Revision (SCL-90-R) were administered to each subject for psychosocial assessment [24,25].

The severity of chronic pain and pain related disability were assessed with the graded chronic pain (GCP) scale [21]. The GCP scale is composed of 7 questions, including characteristic pain intensity (present pain, worst pain, and average pain), disability score (interferences in daily, social, and work activities), and disability days. According to the total score, the GCP severity is classified into five grades (Grade 0, no disability; Grade 1, low disability and low intensity; Grade 2, low disability and high intensity; Grade 3, high disability and moderately limiting; and Grade 4, high disability and severely limiting).

The SCL-90-R is a useful tool for self-assessment of psychological profiles and multiple psychopathological dimensions. It is composed of a total of 90 items, with 9 symptomatological dimensions: somatization (SOM), obsessiveness-compulsiveness (O-C), interpersonal sensitivity (I-S), depression (DEP), anxiety (ANX), hostility (HOS), phobic anxiety (PHOB), paranoid ideation (PAR) and psychoticism (PSY), and 3 global distress indices: the Global Severity Index (GSI), Positive Symptom Total (PST), and Positive Symptom Distress Index (PSDI) [25].

\subsection{Statistical Analysis}

Gender differences in demographics (age, number of systemic comorbidities, trauma history, orthodontic treatment history, and pain duration) were analyzed with the independent $t$-test. Chi-square tests were used for analyzing gender differences on disc displacement, osteoarthritis, headache, subjective insomnia, tinnitus, bruxism, prevalence of each RDC/TMD axis subtype, percentage distributions of TMD symptoms according to the graded chronic pain, and percentage of patients with T-score above 50 in each dimension of SCL-90-R.

Gender differences in T-score of each dimension of SCL-90-R, pain intensity, number of positive muscle palpation, and maximum mouth opening were analyzed with the MannWhitney $\mathrm{U}$ test. Multivariate linear regression analysis was used to analyze association of age, gender, occlusion problem, and number of systemic comorbidities on pain intensity, number of positive muscle palpation, and maximum mouth opening.

All statistical analysis was performed using SPSS 21.0 software (IBM, Chicago, IL, USA). The level of statistical significance was set at $p<0.05$.

\section{Results}

\subsection{Demographic Features, Clinical Characteristics, and RDC/TMD Axis I Profile}

As shown in Table 1, among the TMD patients who visited the TMJ and Orofacial Pain Clinic of Seoul National University Dental Hospital, the prevalence of TMD was higher in women $(75.2 \%)$ than men $(24.8 \%)$, and women $(35.9 \pm 15.7$ years) were significantly older than men $(29.7 \pm 14.8$ years $)(p<0.01)$. Women reported significantly higher pain intensity and number of positive muscle palpation, and lower mandibular range of motion than men $(p<0.05)$. Women showed higher prevalence of myogenous pain and mixed pain, and lower prevalence of arthrogenous pain than men, but this was not quite statistically significant $(p>0.05)$.

There were no significant gender differences in the number of systemic comorbidities, pain duration, trauma history, and orthodontic treatment history. Women showed higher prevalence of headache and subjective insomnia than men $(p<0.01)$, but no significant gender differences were found in tinnitus and bruxism. Women showed higher prevalence of disc displacement without reduction and osteoarthritis, and lower prevalence of disc displacement with reduction than men $(p<0.01)$. 
Table 1. Demographic features and clinical characteristics of the temporomandibular disorder (TMD) patients.

\begin{tabular}{|c|c|c|c|}
\hline & Women & Men & $p$-Value \\
\hline Number of patients & $791(75.2 \%)$ & $261(24.8 \%)$ & \\
\hline Age (years) ${ }^{a}$ & $35.9 \pm 15.7$ & $29.7 \pm 14.8$ & $<0.001$ * \\
\hline $\begin{array}{l}\text { Pain duration } \\
\text { (months) }^{a}\end{array}$ & $31.3 \pm 50.8$ & $30.4 \pm 51.3$ & 0.883 \\
\hline Pain intensity $\mathrm{b}$ & $3.3 \pm 2.5$ & $2.9 \pm 2.5$ & 0.024 * \\
\hline $\begin{array}{l}\text { Number of positive } \\
\text { muscle palpation } b\end{array}$ & $5.2 \pm 5.6$ & $3.7 \pm 5.0$ & $<0.001$ * \\
\hline $\begin{array}{l}\text { Maximum mouth } \\
\text { opening }(\mathrm{mm})^{b}\end{array}$ & $43.5 \pm 8.6$ & $48.1 \pm 8.7$ & $<0.001$ * \\
\hline \multicolumn{4}{|l|}{ Pain origin ${ }^{c}$} \\
\hline Myogenous & $34.9 \%$ & $34.1 \%$ & \multirow{3}{*}{0.051} \\
\hline Arthrogenous & $34.3 \%$ & $44.4 \%$ & \\
\hline Mixed & $30.8 \%$ & $21.4 \%$ & \\
\hline $\begin{array}{l}\text { Number of systemic } \\
\text { comorbidities }^{\text {a }}\end{array}$ & $0.49 \pm 0.89$ & $0.46 \pm 0.87$ & 0.562 \\
\hline Trauma history $^{\mathrm{a}}$ & $12.9 \%$ & $16.5 \%$ & 0.146 \\
\hline $\begin{array}{l}\text { Orthodontic } \\
\text { treatment history }^{a}\end{array}$ & $7.2 \%$ & $4.6 \%$ & 0.140 \\
\hline Headache $^{c}$ & $65.7 \%$ & $46.8 \%$ & $<0.001$ * \\
\hline Subjective Insomnia ${ }^{c}$ & $28.7 \%$ & $19.7 \%$ & $0.004 *$ \\
\hline Tinnitus ${ }^{c}$ & $41.5 \%$ & $34.9 \%$ & 0.069 \\
\hline Bruxism $^{\mathrm{c}}$ & $21.6 \%$ & $26.3 \%$ & 0.119 \\
\hline \multicolumn{4}{|l|}{ Disc displacement ${ }^{\mathrm{C}}$} \\
\hline Normal & $25.2 \%$ & $22.2 \%$ & \multirow{3}{*}{$0.002 *$} \\
\hline $\begin{array}{l}\text { Disc displacement } \\
\text { with reduction }\end{array}$ & $51.8 \%$ & $63.2 \%$ & \\
\hline $\begin{array}{l}\text { Disc displacement } \\
\text { without reduction }\end{array}$ & $23.0 \%$ & $14.6 \%$ & \\
\hline Osteoarthritis ${ }^{\mathrm{c}}$ & $42.4 \%$ & $23.0 \%$ & $<0.001$ * \\
\hline
\end{tabular}

a Results were obtained from independent $t$-test: mean \pm SD. ${ }^{b}$ Results were obtained from Mann-Whitney U test. ${ }^{\mathrm{c}}$ Results were obtained from chi-square test. ${ }^{*}$ Significant difference, $p<0.05$.

\subsection{Graded Chronic Pain}

Gender differences in the percentage distribution of TMD symptoms according to the graded chronic pain are shown in Table 2. Women showed higher percentage of Grade II, III, and IV, and lower percentage of Grade I than men $(p<0.01)$. The high disability group (Grade III and IV) was more frequent in women (44.4\%) than men $(37.1 \%)$.

Table 2. Gender differences in percentage distributions of TMD symptoms according to the graded chronic pain.

\begin{tabular}{ccc}
\hline Graded Chronic Pain & Women & Men \\
\hline Low disability & & \\
Low intensity (I) & $35.1 \%$ & $48.2 \%$ \\
High intensity (II) & $20.5 \%$ & $14.7 \%$ \\
High disability & & \\
Moderate limiting (III) & $26.0 \%$ & $22.0 \%$ \\
Severely limiting (IV) & $18.4 \%$ & $15.1 \%$ \\
\hline$p$-value & & \\
\hline
\end{tabular}

Results were obtained from the Chi-square test. * Significant difference, $p<0.05$.

\subsection{Psychological Profiles}

Gender differences in T-score of each dimension of SCL-90-R are shown in Table 3. Men showed higher score of PHOB dimension and PSDI in SCL-90-R than women $(p<0.01)$. Table 4 showed gender differences in percentage of patients with T-score above 50 in each 
dimension of SCL-90-R. Men showed higher percentage of patients with T-score above 50 in O-C and PSY dimensions than women $(p<0.05)$.

Table 3. Gender differences in T-score of each dimension of SCL-90-R.

\begin{tabular}{cccc}
\hline SCL-90-R & Women & Men & $p$-Value \\
\hline Symptom dimension & & & \\
SOM & $45.9 \pm 8.4$ & $46.5 \pm 9.4$ & 0.601 \\
O-C & $43.6 \pm 15.9$ & $43.4 \pm 9.5$ & 0.891 \\
I-S & $43.5 \pm 14.3$ & $43.8 \pm 9.0$ & 0.488 \\
DEP & $43.2 \pm 9.1$ & $42.5 \pm 9.0$ & 0.432 \\
ANX & $43.2 \pm 8.3$ & $43.6 \pm 8.1$ & 0.096 \\
HOS & $44.8 \pm 7.9$ & $44.7 \pm 7.5$ & 0.465 \\
PHOB & $44.3 \pm 7.8$ & $45.6 \pm 7.8$ & $<0.001^{*}$ \\
PAR & $43.0 \pm 7.9$ & $42.3 \pm 6.9$ & 0.093 \\
PSY & $43.1 \pm 6.9$ & $43.9 \pm 7.6$ & 0.086 \\
\hline Global index & & & \\
GSI & $42.8 \pm 8.6$ & $43.2 \pm 8.5$ & 0.574 \\
PSDI & $44.1 \pm 8.0$ & $45.5 \pm 8.7$ & $0.007 *$ \\
PST & $41.8 \pm 10.5$ & $41.8 \pm 10.8$ & 0.574 \\
\hline
\end{tabular}

SOM, somatization; O-C, obsessive-compulsive; I-S, interpersonal-sensitivity; DEP, depression; ANX, anxiety HOS, hostility; PHOB, phobic anxiety; PAR, paranoid ideation; PSY, psychoticism; GSI, global severity index; PSDI, positive symptom distress index; PST, positive symptom total. Results were obtained from the Mann-Whitney U test. * Significant difference, $p<0.05$.

Table 4. Gender differences in percentage of patients with T-score above 50 in each dimension of SCL-90-R.

\begin{tabular}{cccc}
\hline $\begin{array}{c}\text { Symptom } \\
\text { Dimension }\end{array}$ & Women (\%) & Men (\%) & $p$-Value \\
\hline SOM & 23.0 & 20.7 & 0.124 \\
O-C & 17.3 & 20.7 & $0.039 *$ \\
I-S & 16.6 & 19.2 & 0.058 \\
DEP & 16.9 & 16.9 & 0.129 \\
ANX & 14.2 & 14.6 & 0.122 \\
HOS & 19.0 & 16.1 & 0.104 \\
PHOB & 15.0 & 14.2 & 0.135 \\
PAR & 13.0 & 11.9 & 0.132 \\
PSY & 13.5 & 18.0 & $0.015^{*}$
\end{tabular}

SOM, somatization; O-C, obsessive-compulsive; I-S, interpersonal-sensitivity; DEP, depression; ANX, anxiety; HOS, hostility; PHOB, phobic anxiety; PAR, paranoid ideation; PSY, psychoticism. Results were obtained from Chi-square test. * Significant difference, $p<0.05$.

\subsection{Impact of Gender on Pain Intensity, Number of Positive Muscle Palpation, and Maximum Mouth Opening}

Table 5 showed the association of age, gender, asymmetry of occlusal contacts, and number of systemic comorbidities on pain intensity, number of positive muscle palpation and maximum mouth opening. Gender was significantly associated with number of positive muscle palpation and maximum mouth opening $(p<0.01)$. Pain intensity was not associated with gender, but with number of systemic comorbidities $(p<0.05)$. 
Table 5. Association of age, gender, unbalanced occlusion, and number of systemic comorbidities on pain intensity, number of positive muscle palpation, and maximum mouth opening.

\begin{tabular}{|c|c|c|c|c|c|c|}
\hline & \multicolumn{2}{|c|}{ Pain Intensity } & \multicolumn{2}{|c|}{$\begin{array}{c}\text { Number of Positive Muscle } \\
\text { Palpation }\end{array}$} & \multicolumn{2}{|c|}{ Maximum Mouth Opening } \\
\hline & $\begin{array}{l}\text { Standardized } \\
\text { Coefficient }(\beta)\end{array}$ & $p$-Value & $\begin{array}{l}\text { Standardized } \\
\text { Coefficient }(\beta)\end{array}$ & $p$-Value & $\begin{array}{l}\text { Standardized } \\
\text { Coefficient }(\beta)\end{array}$ & $p$-Value \\
\hline Age & 0.048 & 0.148 & 0.074 & 0.024 * & -0.097 & $0.003 *$ \\
\hline $\begin{array}{c}\text { Gender } \\
(\text { Men = 1, } \\
\text { Women = 2) }\end{array}$ & 0.050 & 0.107 & 0.103 & 0.001 * & -0.208 & $<0.001$ * \\
\hline $\begin{array}{l}\text { Asymmetry of } \\
\text { occlusal } \\
\text { contacts }\end{array}$ & 0.034 & 0.266 & 0.016 & 0.590 & 0.023 & 0.454 \\
\hline $\begin{array}{c}\text { Number of } \\
\text { systemic } \\
\text { comorbidities }\end{array}$ & 0.071 & $0.030 *$ & 0.056 & 0.083 & -0.025 & 0.434 \\
\hline $\begin{array}{l}\text { Adjusted } R^{2} \\
\text { values }\end{array}$ & \multicolumn{2}{|c|}{$0.011 *$} & \multicolumn{2}{|c|}{$0.022 *$} & \multicolumn{2}{|c|}{0.058} \\
\hline
\end{tabular}

Results were obtained from multivariate linear regression analysis. ${ }^{*}$ Significant difference, $p<0.05$.

\section{Discussion}

It is well known that women hold the majority of patients seek for treatment of TMD. Numerous studies reported a female predominance of prevalence of TMD, but there are few studies using diagnostic tools such as RDC/TMD and SCL-90-R for multi-aspect analysis on large sample in Korea. Furthermore, a recent population-based study revealed that gender differences in the prevalence of orofacial pain including TMD are increasing over time [26]. Therefore, it needs to analyze the recent data on gender differences of Korean TMD patients and associations with biological and psychosocial factors. Our study investigated the gender effect on the clinical signs and symptoms of TMD patients, and analyzed its differences based on RDC/TMD and psychosocial characteristics.

Our data showed that the prevalence of TMD in women was about 3 times more than in men (women, $75.2 \%$; men, 24.8\%) and mean age was $35.9 \pm 15.7$ years and $29.7 \pm$ 14.8 years, respectively. The female predominance in TMD shown in the present study is consistent with previous studies. Numerous studies reported that women visited clinics for treatment of TMD about 3-9 times more than men, and women had TMJ pain from 1.5 to 2 times in women than men in the community [6,26]. Meanwhile, the results showed a large standard deviation compared to mean value relatively in the number of systemic comorbidities and pain duration. It might be caused by variation of patients who had chronic pain and various systemic diseases.

The result showed that prevalence of TMJ disc displacement without reduction was higher in women than men. This is consistent with a previous study with using MR image, reporting that women had a higher prevalence of TMJ disc displacement without reduction [27]. Meanwhile, the female predominance in TMJ osteoarthritis (OA) shown in the present study is consistent with previous studies $[28,29]$. The reason for this result is unclear, but may be affected by differences of sex hormones, pain perception, response to stress, and psychological factors. However, there are other epidemiologic studies showing opposite results in the prevalence of TMJ OA. Some investigators have indicated that the actual changes in joint morphology do not have any statistically significant gender differences [30,31], and some even suggested a higher incidence of $\mathrm{OA}$ in men [32,33]. These differences could be caused by the differences of diagnostic methods and the complexity of the disease.

In this study, women showed higher prevalence of headache and subjective insomnia than men. Female predominance of headache is consistent with the previous global survey 
of headache epidemiology, reporting that the average headache prevalence was $37 \%$ in men and 52\% in women [34]. The prevalence of insomnia was also higher in girls than boys in the study with the general population of young children [35].

Though several studies have reported the association with TMD and tinnitus, the mechanism is not understood yet. The present study revealed that women suffered from tinnitus more than men, and it is consistent with previous study that reported that tinnitus with TMD were more frequently in women on the case-control study [5]. However, there was no statistically significant gender difference in the prevalence of tinnitus in this study.

Moreover, the result showed that there was no statistically significant gender difference in the prevalence of bruxism. Many clinicians have considered oral habits, such as bruxism and clenching as possible risk factors of TMD, and some studies reported female predominance in the prevalence of bruxism [13]. However, the specific relationship between clinical symptoms of TMD and bruxism is not well known and scientific literatures have indicated weak evidences for the relationship [36,37].

In our study, women had a higher level of disability in the graded chronic pain than men. The levels of disability were higher in women in grade II, III, and IV in men, respectively, and higher in men in grade than women. Since the graded pain status was associated with enduring patterns of behavior and increased psychological impairment, the results suggest that women affected from TMJ pain more than men, and it may be associated with pain sensitivity and psychological characteristics.

Usually TMD patients show increased somatization, anxiety, depression, and stress [38,39]. Interestingly, our study showed that men had higher T-scores of PHOB and PSDI of SCL-90-R than women. When considered with T-score above 50, we found that O-C and PSY were higher in men than women. These findings are in contrast to several results that showed female patients exhibited significantly higher anxiety, stress, and higher muscle tension than male $[17,18]$. In the other hand, several studies agree with these results that there were no significant gender differences on depression and somatization [20]. Based on these results, we can speculate that male patients, who visit the clinic for treatment of TMD, may have a higher tendency of psychological problems in some aspect than female patients. Recently, increasing evidence suggested that there might be stronger association between psychological profile, such as anxiety and pain responses among men than women [40]. Several laboratory studies also have indicated that anxiety is positively associated with pain sensitivity among men, but not women [41,42].

Our data showed that pain intensity, number of positive muscle palpation, and the ratio of myogenous pain and mixed pain group were significantly higher in women than men. Meanwhile, the ratio of arthrogenous pain group and maximum mouth opening were higher in men than women. Multivariate linear regression analysis suggested that gender and age are associated with the number of positive muscle palpation and maximum mouth opening. These results support that women are more at risk in the progression and development of muscular pain than men. It can be explained with several evidences that women have smaller muscle fibers and higher frequency of type I fibers than men and have increased jaw muscle reflex responses to glutamate injection to jaw muscles [43-46]. In maximum mouth opening, gender difference may be caused by anatomical gender differences in mandibular height. The results also showed mouth opening limitation with age, and it could be a risk factor of frailty in elder people. Interestingly, the results showed that pain intensity was not associated with gender. While some studies have reported greater pain severity among women than men $[47,48]$, another study has found no gender difference in pain severity among treatment-seeking patients [49]. Laboratory research also have failed in producing an obvious and consistent pattern of gender differences in human pain sensitivity with stimuli [50].

Various etiological factors for the female predominance of TMD can be suggested in this study. Firstly, the biological and physiological differences, such as hormonal changes, differences in pain response to noxious stimuli, and musculature have been suggested as important etiological factors [51-53]. Ovarian hormones and hormonal changes in 
menstrual cycles and postmenopausal years affect pain level and severity [54]. Secondly, for the genetic factors that can contribute to pain perception, proinflammatory cytokines and extracellular matrix breakdown may affect the female predilection [55]. Thirdly, the psychosocial factors that contain an enhanced response to stress stimuli, distress, anxiety, depression, or reduced coping strategies have been reported to make gender differences [56-59].

This study has several limitations, in particular the retrospective design and the limited diagnostic methods for some disease. We only used the conventional X-ray for diagnosis of osteoarthritis, and questionnaire for diagnosis of bruxism. It can suggest more accurate data for analysis by using cone beam CT or polysomnography. Furthermore, this study used only GCPS and SCL-90-R as psychological tools. More multifactorial analysis would be possible by using various psychological evaluation tools such as, Oral Health Impact Profile-14 questionnaire (OHIP-14) [60], Jaw Functional Limitation Scale (JFLS)20 [61], Oral Behavior Checklist (OBC) [62], Generalized Anxiety Disorder (GAD)-7 [63], and Patient Health Questionnaire (PHQ)-15 [64]. Nevertheless, the strengths of this study are large sample size and multi-aspect analysis with clinical assessment and psychosocial considerations by using RDC/TMD and SCL-90-R.

\section{Conclusions}

The result of this study showed that women had a higher prevalence of TMD and comorbidities, and a higher level of the severity of chronic pain and a tendency of myogenous pain than men in Korean TMD patients. Our results suggest that gender is associated with muscle pain of TMD and psychological profiles, but not with pain intensity. To achieve understanding of patient and increase of success rate of treatment of TMD, gender should be considered in patient evaluations and treatment approaches.

Author Contributions: Conceptualization, J.W.C.; Methodology, J.H.J.; Software, J.H.J.; Validation, J.H.J. and J.W.C.; Formal Analysis, J.H.J.; Investigation, J.H.J.; Resources, J.H.J.; Data Curation, J.H.J.; Writing-Original Draft Preparation, J.H.J. and J.W.C.; Writing-Review and Editing, J.H.J. and J.W.C.; Visualization, J.H.J.; Supervision, J.W.C.; Project Administration, J.W.C. All authors have read and agreed to the published version of the manuscript.

Institutional Review Board Statement: The study was conducted according to the guidelines of the Declaration of Helsinki, and approved by the Institutional Review Board of the Seoul National University Dental Hospital (CRI 15006).

Informed Consent Statement: Informed consent was obtained from all subjects involved in the study.

Data Availability Statement: The data published in this research are available on request from the first author and corresponding authors.

Funding: This research received no external funding.

Conflicts of Interest: The authors declare no conflict of interest.

\section{References}

1. Cooper, B.C.; Kleinberg, I. Examination of a large patient population for the presence of symptoms and signs of temporomandibular disorders. CRANIO 2007, 25, 114-126. [CrossRef] [PubMed]

2. Lipton, J.A.; Ship, J.A.; Larach-Robinson, D. Estimated prevalence and distribution of reported orofacial pain in the United States. J. Am. Dent. Assoc. 1993, 124, 115-121. [CrossRef] [PubMed]

3. Locker, D.; Slade, G. Prevalence of symptoms associated with temporomandibular disorders in a Canadian population. Community Dent. Oral Epidemiol. 1988, 16, 310-313. [CrossRef] [PubMed]

4. Progiante, P.S.; Pattussi, M.P.; Lawrence, H.P.; Goya, S.; Grossi, P.K.; Grossi, M.L. Prevalence of temporomandibular disorders in an adult Brazilian community population using the research diagnosis criteria (Axes I and II) for temporomandibular disorders (The Maringá Study). Int. J. Prosthodont. 2015, 28, 600-609. [CrossRef]

5. Martínez, C.C.; Santillana, I.E.A.; Lavín, A.M.W.; Tostado, F.L. Prevalence of temporomandibular disorders according to RDC/TMD, in patients of a sub-urban community of Puebla, Mexico. Rev. Colomb. Investig. Odontol. 2013, 4, 1-9. 
6. Li, W.; Cheng, Y.; Wei, L.; Li, B.; Zheng, H. Gender and age differences of temporomandibular joint disc perforation: A cross-sectional study in a population of patients with temporomandibular disorders. J. Craniofac. Surg. 2019, 30, 1497-1498.

7. Schmid-Schwap, M.; Bristela, M.; Kundi, M.; Piehslinger, E. Sex-differences in patients with temporomandibular disorders. J. Orofac. Pain 2013, 27, 42-50. [CrossRef]

8. Chatzopoulos, G.S.; Sanchez, M.; Cisneros, A.; Wolff, L.F. Prevalence of temporomandibular symptoms and parafunctional habits in a university dental clinic and association with gender, age, and missing teeth. CRANIO 2019, 37, 159-167. [CrossRef]

9. Wieckiewicz, M.; Rychowska, N.; Wojciechowski, K.; Pelc, A.; Augustyniak, M.; Sleboda, A.; Zietek, M. Prevalence and correlation between TMD based on RDC/TMD diagnoses, oral parafunctions and psychoemotional stress in Polish UniversityStudents. Biomed. Res. Int. 2014, 472346, 1-7.

10. Velly, A.M.; Gornitsky, M.; Phlippe, P. Contributing factors to chronic myofascial pain: A case-control study. Pain 2003, 104, 491-499. [CrossRef]

11. Karibe, H.; Goddard, G.; Gear, R.W. Sex differences in masticatory muscle pain after chewing. J. Dent. Res. 2003, 82, 112-116. [CrossRef]

12. Bagis, B.; Ayaz, E.A.; Turgut, S.; Durkan, R.; Özcan, M. Gender difference in prevalence of signs and symptoms of temporomandibular joint disorders: A retrospective study on 243 consecutive patients. Int. J. Med. Sci. 2012, 9, 539-544. [CrossRef]

13. Bertoli, F.M.P.; Bruzamolin, C.D.; Pizzatto, E.; Losso, E.M.; Brancher, J.A.; de Souza, J.F. Prevalence of diagnosed temporomandibular disorders: A cross-sectional study in Brazilian adolescents. PLoS ONE 2018, 13, e0192254. [CrossRef]

14. Agelberg, G.; Carlsson, G.E. Functional disorders of the masticatory system. Distribution of symptoms according to age and sex as judged from investigation by questionnaire. Acta Odontol. Scand. 1972, 30, 597-604. [CrossRef]

15. Zarb, G.A.; Carlsson, G.E. Temporomandibular Joint Function and Dysfunction; Munksgaard: Copenhagen, Denmark, 1979.

16. Clark, G.T.; Solberg, W.K. Perspectives in Temporomandibular Disorders; Quintessence Publishing: Chicago, IL, USA, 1987.

17. Canales, G.T.; Guarda-Nardini, L.; Rizzatti-Barbosa, C.M.; Conti, P.C.R.; Manfredini, D. Distribution of depression, somatization and pain-related impairment in patients with chronic temporomandibular disorders. J. Appl. Oral Sci. 2019, 27, e20180210. [CrossRef]

18. Staniszewski, K.; Lygre, H.; Bifulco, E.; Kvinnsland, S.; Willassen, L.; Helgeland, E.; Berge, T.; Rosén, A. Temporomandibular Disorders Related to Stress and HPA-Axis Regulation. Pain Res. Manag 2015, 702751. [CrossRef]

19. Wiesenfeld-Hallin, Z. Sex differences in pain perception. Gend. Med. 2005, 2, 137-145. [CrossRef]

20. Yap, A.U.J.; Dworkin, S.F.; Chua, E.K.; List, T.; Tan, K.B.C.; Tan, H.H. Prevalence of temporomandibular disorder subtypes, psychologic distress, and psychosocial dysfunction in Asian patients. J. Orofac. Pain 2003, 17, 21-28.

21. Von Korff, M.; Ormel, J.; Keefe, F.J.; Dworkin, S.F. Grading the severity of chronic pain. Pain 1992, 50, 133-149. [CrossRef]

22. Dworkin, S.F.; LeResche, L. Research diagnostic criteria for temporomandibular disorders: Review, criteria, examinations and specifications, critique. J. Craniomandib. Disord. 1992, 6, 301-355.

23. Ciancaglini, R.; Gherlone, E.F.; Radaelli, G. Unilateral temporomandibular disorder and asymmetry of occlusal contacts. J. Prosthet. Dent. 2003, 89, 180-185. [CrossRef]

24. Sohn, B.J.; Park, M.W.; Park, J.W.; Chung, S.C.; Chung, J.W. Reliability of the Korean version of research diagnostic criteria for temporomandibular disorders (RDC/TMD). J. Oral Med. Pain 2008, 33, 323-331.

25. Derogatis, L.R. SCL-90-R: Administration, Scoring and Procedures Manual; Clinical Psychometric Research: Baltimore, MD, USA, 1977.

26. de Leeuw, R.; Kasser, G.D. Orofacial Pain: Guidelines forAssessment, Diagnosis, and Management, 5th ed.; Quintessence Publishing: Hanover Park, IL, USA, 2013.

27. Kwon, H.B.; Kim, H.; Jung, W.S.; Kim, T.W.; Ahn, S.J. Gender differences in dentofacial characteristics of adult patients with temporomandibular disc displacement. J. Oral Maxillofac. Surg. 2013, 71, 1178-1186. [CrossRef]

28. Kim, K.; Wojczyńska, A.; Lee, J.Y. The incidence of osteoarthritic change on computed tomography of Korean temporomandibular disorder patients diagnosed by RDC/TMD; a retrospective study. Acta Odontol. Scand. 2016, 74, 337-342. [CrossRef]

29. Alzahrani, A.; Yadav, S.; Gandhi, V.; Lurie, A.G.; Tadinada, A. Incidental findings of temporomandibular joint osteoarthritis and its variability based on age and sex. Imaging Sci. Dent. 2020, 50, 245-253. [CrossRef]

30. Widmalm, S.E.; Westesson, P.L.; Kim, I.K.; Pereira, F.J., Jr.; Lundh, H.; Tasaki, M.M. Temporomandibular joint pathosis related to sex, age, and dentition in autopsy material. Oral Surg. Oral Med. Oral Pathol. 1994, 78, 416-425. [CrossRef]

31. Axelsson, S.; Fitins, D.; Hellsing, G.; Holmlund, A. Arthrotic changes and deviation in form of the temporomandibular joint-An autopsy study. Swed. Dent. J. 1987, 11, 195-200.

32. Magnusson, C.; Ernberg, M.; Magnusson, T. A description of a contemporary human skull material in respect of age gender, temporomandibular joint changes, and some dental vaiables. Swed. Dent. J. 2008, 32, 69-83.

33. Richards, L.C. Degenerative changes in the temporomandibular joint in two Australian Aboriginal populations. J. Dent. Res. 1988, 67, 1529-1533. [CrossRef]

34. Manzoni, G.C.; Stovner, L.J. Epidemiology of headache. Handb. Clin. Neurol. 2010, 97, 3-22.

35. Calhoun, S.L.; Fernandez-Mendoza, J.; Vgontzas, A.N.; Liao, D.; Bixler, E.O. Prevalence of insomnia symptoms in a general population sample of young children and preadolescents: Gender effects. Sleep Med. 2014, 15, 91-95. [CrossRef] [PubMed]

36. Baad-Hansen, L.; Thymi, M.; Lobbezoo, F.; Svensson, P. To what extent is bruxism associated with musculoskeletal signs and symptoms? A systematic review. J. Oral Rehabil. 2019, 46, 845-861. [CrossRef] [PubMed] 
37. Jiménez-Silva, A.; Peña-Durán, C.; Tobar-Reyes, J.; Frugone-Zambra, R. Sleep and awake bruxism in adults and its relationship with temporomandibular disorders: A systematic review from 2003 to 2014. Acta Odontol. Scand. 2017, 75, 36-58. [CrossRef] [PubMed]

38. Sójka, A.; Stelcer, B.; Roy, M.; Mojs, E.; Pryliński, M. Is there a relationship between psychological factors and TMD? Brain Behav. 2019, 9, e01360. [CrossRef]

39. Akhter, R.; Morita, M.; Esaki, M.; Nakamura, K.; Kanehira, T. Development of temporomandibular disorder symptoms: A 3-year cohort study of university students. J. Oral Rehabil. 2011, 38, 395-403. [CrossRef]

40. Jones, A.; Zachariae, R. Gender, anxiety, and experimental pain sensitivity: An overview. J. Am. Med. Womens Assoc. 2002, 57, 91-94.

41. Jones, A.; Zachariae, R. Investigation of the interactive effects of gender and psychological factors on pain response. Br. J. Health Psychol. 2004, 9, 405-418. [CrossRef]

42. Fillingim, R.B.; Keefe, F.J.; Light, K.C.; Booker, D.K.; Maixner, W. The influence of gender and psychological factors on pain perception. J. Gend. Cult. Health 1996, 1, 21-36.

43. Cairns, B.E.; Hu, J.W.; Arendt-Nielsen, L.; Sessle, B.J.; Svensson, P. Sex-related differences in human pain and rat afferent discharge evoked by injection of glutamate into the masseter muscle. J. Neurophysiol. 2001, 86, 782-791. [CrossRef]

44. Toft, I.; Lindal, S.; Bonaa, K.H.; Jenssen, T. Quantitative measurement of muscle fiber composition in a normal population. Muscle Nerve 2003, 28, 101-108. [CrossRef]

45. Roberts, B.M.; Lavin, K.M.; Many, G.M.; Thalacker-Mercer, A.; Merritt, E.K.; Bickel, C.S.; Mayhew, D.L.; Tuggle, S.C.; Cross, J.M.; Kosek, D.J.; et al. Human neuromuscular aging: Sex differences revealed at the myocellular level. Exp.Gerontol. 2018, 106116, 124. [CrossRef]

46. Roberts, B.M.; Nuckols, G.; Krieger, J.W. Sex Differences in Resistance Training: A Systematic Review and Meta-Analysis. J. Strength Cond. Res. 2020, 34, 1448-1460. [CrossRef]

47. Fillingim, R.B.; Doleys, D.M.; Edwards, R.R.; Lowery, D. Clinical characteristics of chronic back pain as a function of gender and oral opioid use. Spine 2003, 28, 143-150. [CrossRef]

48. Keefe, F.J.; Lefebvre, J.C.; Egert, J.R.; Affleck, G.; Sullivan, M.J.; Caldwell, D.S. The relationship of gender to pain, pain behavior, and disability in osteoarthritis patients: The role of catastrophizing. Pain 2000, 87, 325-334. [CrossRef]

49. Edwards, R.R.; Augustson, E.; Fillingim, R.B. Differential relationships between anxiety and treatment-associated pain reduction among male and female chronic pain patients. Clin. J. Pain 2003, 19, 208-216. [CrossRef]

50. Racine, M.; Tousignant-Laflamme, Y.; Kloda, L.A.; Dion, D.; Dupuis, G.; Choiniere, M. A systematic literature review of 10 years of research on sex/gender and experimental pain perception-Part 1: Are there really differences between women and men? Pain 2012, 153, 602-618. [CrossRef]

51. LeResche, L.; Mancl, L.; Sherman, J.J.; Gandara, B.; Dworkin, S.F. Change in temporomandibular pain and other symptoms across the menstrual cycle. Pain 2003, 106, 253-261. [CrossRef]

52. Dao, T.T.; LeResche, L. Gender differences in pain. J. Orofac. Pain 2000, 14, 169-184.

53. Fox, J.; Garber, P.; Hoffman, M.; Johnson, D.; Schaefer, P.; Vien, J.; Zeaton, C.; Thompson, L.V. Morphological characteristics of skeletal muscles in relation to gender. AgingClin. Exp. Res. 2003, 15, 264-269. [CrossRef]

54. Dao, T.T.; Knight, K.; Ton-That, V. Modulation of myofascial pain by the reproductive hormones: A preliminary report. J. Prosthet. Dent. 1998, 79, 663-670. [CrossRef]

55. Oakley, M.; Vieira, A.R. The many faces of genetics contribution to temporomandibular joint disorder. Orthod. Craniofac. Res. 2008, 11, 125-135. [CrossRef]

56. Madariaga, V.I.; Jasim, H.; Ghafouri, B.; Ernberg, M. Myogenous temporomandibular disorders and salivary markers of oxidative stress-A cross-sectional study. J. Oral Rehabil. 2021, 48, 1-9. [CrossRef]

57. Sannajust, S.; Imbert, I.; Eaton, V.; Henderson, T.; Liaw, L.; May, M.; Barbe, M.F.; King, T. Females have greater susceptibility to develop ongoing pain and central sensitization in a rat model of temporomandibular joint pain. Pain 2019, 160, $2036-2049$. [CrossRef]

58. Gill, J.M.; Szanton, S.L.; Page, G.G. Biological underpinnings of health alterations in women with PTSD: A sex disparity. Biol. Res. Nurs. 2005, 7, 44-54. [CrossRef]

59. Bäck, K.; Hakeberg, M.; Wide, U.; Hange, D.; Dahlström, L. Orofacial pain and its relationship with oral health-related quality of life and psychological distress in middle-aged women. Acta Odontol. Scand. 2020, 78, 74-80. [CrossRef]

60. Slade, G.D.; Spencer, A.J. Development and evaluation of the oral health impact profile. Community Dent. Health $1994,11,3-11$.

61. Ohrbach, R.; Larsson, P.; List, T. The jaw functional limitation scale: Development, reliability, and validity of 8-item and 20- item versions. J.Orofac. Pain 2008, 22, 219-230.

62. Markiewicz, M.R.; Ohrbach, R.; McCall, W.D., Jr. Oral behaviors checklist: Reliability of performance in targeted waking-state behaviors. J. Orofac. Pain. 2006, 20, 306-316.

63. Lowe, B.; Decker, O.; Muller, S. Validation and standardization of the Generalized Anxiety Disorder Screener (GAD-7) in the general population. Med. Care 2008, 46, 266-274. [CrossRef]

64. Kroenke, K.; Spitzer, R.L.; Williams, J.B. The PHQ-15: Validity of a new measure for evaluating the severity of somatic symptoms. Psychosom. Med. 2002, 64, 258-266. [CrossRef] 